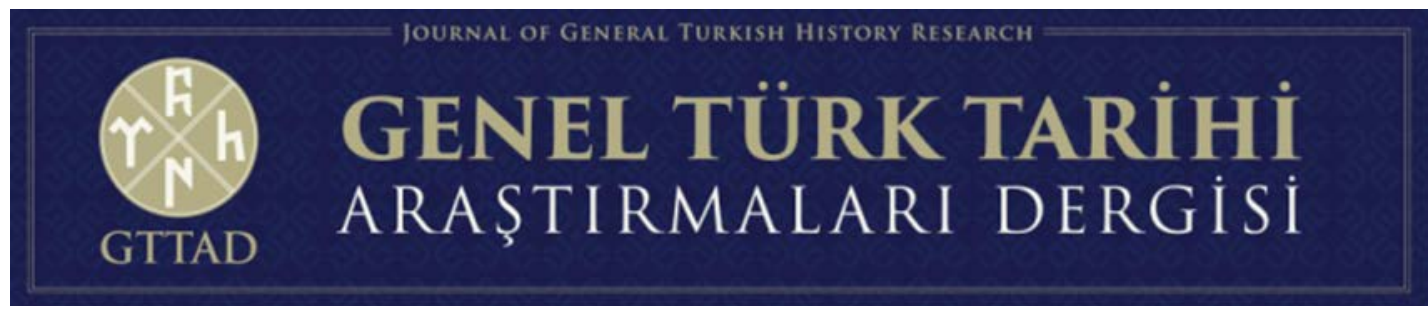

Cilt/Volume 3, Sayı/Issue 6, Temmuz/July 2021, ss. 199-212.

Geliş Tarihi-Received Date: 18.05.2021 Kabul Tarihi-Accepted Date: 07.07.2021

ARAŞTIRMA MAKALESİ - RESEARCH ARTICLE

OĞUZ KAĞAN DESTANI'NDA İSKÂN: YAYLAK VE KIŞLAKLAR

HİKMET DEMİRCI'-SELİME İNAN**

ÖZ

Türkler, tarih boyunca çok geniş ve farklı coğrafyalarda hâkimiyet sürdü. Türklerin geniş ve farklı coğrafyalarda hâkimiyet sürmesi göçebeliğine bağlandı ve yaylak-kışlak hayatı yaşamaları batı literatüründe genellikle göçebelik çerçevesinde "barbar" kavramıyla özdeşleştirildi. Türkiye'de yapılan çalışmalarda ise göçebelikten ziyade yaşam tarzından yola çıkılarak bozkır kültürü, konargöçer veya atlı göçerevli kültür içerisinde değerlendirildi. Göçebelik, Dünya'da (Afrika, Ortadoğu, Yakın Doğu gibi) birçok topluluk tarafından benimsendi, ancak Türk atlı göçerevliliği diğerlerinden farklı olduğu gibi dünya medeniyetine önemli katkılarda bulunan (atın evcilleştirilmesi, askeri strateji /techizat, giyim- kuşam ve yiyecek vb) bir medeniyet olarak kabul edildi. Bu sebeple, Türkün dünya görüşüne, sosyal yaşam tarzına, hayvancılığa bağlı durumlarda ortaya çıkan göçebelik ile yeri yurdu belli olmayan bazı kavimlerin yaşadıkları göçebeliği birbirine karıştırmamak gerekir. Atlı göçerevli toplulukların diğer yerleşik topluluklara nazaran teşkilatlanmayı ve devletleşmeyi gerçekleştiremeyeceği, onların medeniyet ve kültürünün diğer toplulukları etkilemeyeceği de düşünülmemelidir. Tarihi süreçte, atlı göçerevli topluluk diğer yerleşik topluluklar gibi teşkilatlanabilir, devletleşebilir ve toplulukları etkileyebilir.

Türk kültürünün medeniyet seviyesine ulaşmasında atlı göçerevli yaşam tarzının önemli bir yeri vardır. Atlı göçerevli kültürde, atlarla uzak mesafelere aileriyle / boylarıyla hızla hareket eden Türk toplulukları, teşkilat ve düzenlerini sağladı, yeni yurtlar elde etti. Atlı - göçerevli yaşamda yaylak - kışlaklar, Türklerin yaşadıkları coğrafya içinde teşkilatlandırdığı merkezî yerlerdi. Yaylak ve kışlakların, Türkistan coğrafyasının iklimsel özelliklerine ve ekonomilerinin temeli olan hayvanların beslenmesine bağlı ortaya çıktığı görüldü. Yaylak ve kışlaklar üzerinde bir düzen ve hukukun varlığı, otlaklar üzerinde hayvanlarıyla aile / boy mülkiyetinin hüküm sürmesi kargaşayı önlediği gibi yurtların kalıcılığını da sağladı. Buna bağlı olarak, kadim zamanları aydınlatan Oğuz Kağan Destanı, toplumun dünya görüşü, sahip olduğu inanç ve değerleri, sosyal yapısı hakkında önemli bilgiler verdi. Oğuz Kağan Destanı, atlı göçerevli hayat tarzını ve kültürünü temsil ederek ideal insan tipini resmetti.

Makalede görüleceği gibi Oğuz Kağan Destanı temel alınarak atlı göçerevli yaşam tarzıyla yurt edindikleri yaylak ve kışlak ilişkisi ile konu açıklığa kavuşturuldu. Makalenin yöntemi, destanın içerik çözümlemesi, göçebelik hakkındaki kuramsal yaklaşımların analizi ve eleştirisidir. Makale kapsamında, göçebelik, konargöçerlik veya atlı göçerevli terimleri incelendi, destan üzerinde yaşam tarzı tartışıldı, destanda yaylak ve kışlakların nasıl belirlendiği ve nereler olduğu üzerinde duruldu. Bu konunun inceleme aşamasında, Türklerin yaylak ve kışlaklar arasındaki hareket süreci ve tesir alanlarının günümüzdeki bazı coğrafi karşılıkları kıstas alınacaktır. Söz konusu destanda, yaylak kışlak hayatının ilk kuruluş özellikleri, bölgeleri, yaylak ve kışlakların töre ve orun, ülüş sistemiyle bağlantısı, boylar arasında paylaştırıldığı, yaylak ve kışlaklara mevsimlik göçün yaşandığı ortaya çıktı. Atlı göçer yaşamın devletten bağımsız veya başıboş şekilde gerçekleşmediği de görüldü.

Anahtar Kelimeler: Türk Kültürü, Oğuz Kağan Destanı, Atlı Göçerevli, Mekân, Yaylak, Kışlak.

\footnotetext{
${ }^{*}$ Dr. Öğr. Üyesi, Kahramanmaraş Sütçü İmam Üniversitesi, Fen-Edebiyat Fakültesi, Tarih Bölümü, E-Posta: hdemirci@ksu.edu.tr, ORCID ID: 0000-0001-8756-5909

** Yüksek Lisans Öğrencisi, Kahramanmaraş Sütçü İmam Üniversitesi, Sosyal Bilimler Enstitüsü, Tarih Anabilim Dalı, Genel Türk Tarihi Bilim Dalı, E-Posta: selimeinan56@outlook.com, ORCID ID: 0000-0003-0796-9060.
} 


\title{
OĞUZ KAĞAN DESTANI'NDA İSKÂN: YAYLAK VE KIŞLAKLAR
}

\section{INHABITING IN THE EPIC OF OGUZ KHAN: THE SUMMER PASTURE AND WINTER QUARTERS}

\begin{abstract}
The Turks has dominated wide and diverse range geographies throughout history. The Turks' dominance in different geographies is attributed to their nomadism, and plateau-winter life is generally associated with the concept of "barbarian" in Western literature within the framework of nomadism. The steppe culture is shown within the migrant settler or horse-riding steppe culture, which is evaluated on the lifestyle rather than nomadism, especially in the studies in the Turkey. Many communities around the world have adopted nomadic lifestyles (such as those in Africa, the Middle East, and the Near East), however Turkic horse - riding steppe culture is unique in that it has made significant contributions to world civilization (such as horse domestication, military equipment and strategy, clothing and food, and so on) it was regarded as a civilization. As a result, it should not be confused with nomadism, which occurs in situations related to Turkic worldview, social life, and animal husbandry, and nomadism of tribes inhabited by some nations whose homeland is unknown. It should not be assumed that nomadic societies on horse- riding culture cannot organize and state in the same direction that other settled societies can, and that their civilization and culture will have no impact on other communities. In the historical process, like many other settled societies, horse-riding steppe culture can organize, govern, and influence their communities.
\end{abstract}

The life style of the horse riding steppe has plays an important role in Turk culture as it reaching toward civilization. The horse- riding steppe culture, Turk communities that move rapidly with their families / tribes to long distances by horses maintain their organization and order, and acquired new dormitories. The plateau and winter quarters are the central places organized by the Turks within the geography in which they live in the horse- riding steppe life. Plateaus and winter quarters arosed as a result of Turkestan geography's climatic characteristics and the feeding of animals, which are the basis of economies. The presence of order and law on the plateaus and winterlands, as well as the prevalence of family / tribe ownership of pastures with their animals, prevents chaos and ensures the dormitories' long-term survival. As far as is known, epics that reveal the oldest times was provided important information about the world view of the society inhabited, its beliefs and values, and its social structure. With this in mind, in the Oguz Khan, which is one of the important examples of the steppe lifestyle, represents the horse- riding steppe lifestyle and culture, and the ideal human type. Therefore, the subject was clarified with the relationship between the nomadic life style of the horse and the highlands and winter quarters they had settled in, according to the Oguz Khan epic.

As will be seen in the article, a relationship was established between the pastures and winter quarters, where the horse- riding steppe lifestyle, the places and waters suitable for the steppe life culture of the Turks, settled on the basis of the Oguz Khan Epic. The method of the article is the content resolution of the epic, the analysis and criticism of the theoretical approaches about nomadism. The subject was clarified based on the epic of the Oghuz Khan by establishing a relationship between the nomadic life style of the horse and the pastures and winter quarters where they settled. While the terms nomad, nomadic, or horse-riding steppe terms were discussed in the article, it was determined how and where the pastures and winter quarters were in the Oguz Khan epic. Within the limits of the article, the terms of nomadic, migrant settler, or horse- riding steppe were examined within the scope of the article, as was the life style on the epic, as well as how the plateaus and winter quarters were determined and where they were located. The movement process of the Turks between the summer pasture and winter quarters, as well as their current geographical counterparts, will be used as a criterion in the examination phase of this subject. It is possible to list the results of this article as follows: It emerged that the establishment of the plateaus and winter quarters were closely connected with the tore (yasa) and orun (position) - ülüş (share among members of a dynastic family), as well as being shared between the tribes in seasonal and specific times. It was also found that the horse-riding steppe life was also revealed to not be autonomous or free from the state.

Keywords: Turkic Culture, Epic of Oguz Kagan, Horse- Riding Steppe Culture, Place, The Plateaus, The Winter Quarters. 


\section{GíRiş}

Tarihte Türkler, kadim zamanlarda göçebe olarak tanımlandı. Türklerin günlük yaşam alışkanlıkları söz konusu olduğunda Batılı ve Rus araştırmacılar, göçebe terimini barbar, medeniyetsiz, yerleşik olmayan, başıboş anlamında kullandı. Türklerin göçebeliği noktasında, onların hayvan yetiştiriciliğine dayanan ekonomileri sebebiyle doğuştan göçebe olduğuna dair söylemler ve kuramlar (Marksist) geliştirildi. Türkiye'de yapılan çalışmalarda Türklerin göçebe olmalarından ziyade onların dünya kültürüne ve medeniyetine katkıları ele alındı. Türklerin bozkır kültüründe, atlı göçerevli ${ }^{1}$ oldukları, çoban kültürüne, konargöçer kültüre sahip oldukları ve göçebe olarak değerlendirilemeyeceğine vurgu yapıldı. Genellikle atlı göçerevli kültürün at, koyun ve demir gibi unsurları ve onları kullanma kabiliyetleriyle Türk kültürüne haklı atıflarda bulunuldu.

Atlı göçerevli kültürde, insan ve toplulukların özgür hareket etmeleri ve yeri yurdu belli olmayan yaşam alışkanlıklarından ziyade sistematik ve devam edegelen bir düzen mevcuttur. Oğuz Kağan Destanı, Oğuz Kağan'ın devletini teşkilatlandırması, yaylak ve kışlak yerlerini belirlemesi, Oğuz Kağan etrafında toplanan boyların ülüş̧̧ü (paylaşımcı) bir Türk devlet tipinin çekirdeğini ve özelliklerini gösterir. Bu noktada, Türklerde yaylak ve kışlak hayatının önemli özellikleri, hareket ve tesir alanları değerlendirilecektir. Bilindiği üzere, bu devlet teşkilatlanmasını tarihî gelişim noktaları açısından ele almak önemlidir, Oğuz Kağan Destanı ise kaynak açısından bizleri başlangıç noktasına götürmektedir.

\section{Oğuz Kağan Destanı Varyantlarının Atlı Göçerevli Yaşam Tarzına Göre İncelenmesi}

Milletlerin yaşamsal özelliklerini, düşünce ve inançlarını araştırırken en eski zamanları aydınlatmada birinci derecede önem taşıyan kültürel kaynaklar, destan, menkıbe ve efsanelerdi. Destanların ana kaynak olmasının nedeni ise destanlarda olaylar, tabiatüstü varlıklar üzerinden mübalağalı anlatılsa da esas kültürel düşünce sistemini yansıtarak tarihî hakikatleri ortaya koymasıyd. ${ }^{2}$ Milli destanların ilk müellifleri milletin kendisi olduğu için destanlar bir ferdin ya da sanatkârın değil bir milletin kendi yaşamının sonucu ortaya çıkmış müşterek bir mahsul ürünüydü. ${ }^{3}$ Dünya milletleri içinde köklü bir kültüre sahip Türkler, yazılı edebiyat noktasında kadim zamanları aydınlatma eksiklikleri mevcut ise de Türkler destanlar noktasında zengin bir millettir. Bu destanların arasında Oğuz Kağan Destanı da Türk milleti ve akraba toplulukları için geçmişi aydınlatmada önemli bir kaynak durumundadır. ${ }^{4}$ Türk edebiyatında yazılı dönemlerin göstergesi olan destan terimi, dilimize İslamiyet sonrası dönemde Farsçadan "efsane, masal, hikayet-i güzeştegan," anlamlarında kullanılan "dâstan" kelimesinden geçti. Türk halk edebiyatı içinde hem olağanüstü kahramanlık anlatılarından sonra ortaya çıkan halk hikâyelerinde hem de hece vezniyle yazılan âşık şiirinde görüldü. Batı dillerinde destan terimine karşılık "epos”, “épique”, "epopée”, "epic”. "légende" terimleri kullanıld1. ${ }^{5}$ Ziya Gökalp, destan kelimesi yerine "menkıbe" ifadesini kullanırken Fuat Köprülü, "milli destan" ifadesini kullanmayı tercih etti. ${ }^{7}$

Oğuzların atası Oğuz Kağan ve oğullarının destanını anlatan başlıca iki kaynak elimizde bulunmaktadır. Bunlardan birincisi, Paris kütüphanesinde bulunan Uygur harfleriyle yazılan eksik, yazma nüshadır. "Oğuz Kağan Destanı”, Rıza Nur tarafindan keşfedilerek ilmî olarak W.Bang ve R.Rahmeti Arat tarafindan Almancaya (1932) daha sonra 1936 yılında Türkçeye çevrildi. Muharrem Ergin aynı eseri Millı̂ Eğitim Bakanlığının çıkardığı 1000 Temel Eser serisinde de yayınlandı. Oğuz Kağan Destan'ının Farsça varyantı, İlhanlı sarayında yaşamış Doktor Reşideddin Fazlullah'ın aktardığı Oğuz Kağan ve oğullarına ait rivayetlerdi. Bu eser, İstanbul Topkapı sarayındadır. Faruk Sümer, Reşideddin'in “Cami'üt Tevârih"de doğrudan doğruya sözlü kaynaklardan yararlandığını söylese de Uygurca Oğuz Kağan Destanı'ndan faydalanmadı, Zeki Velidi Togan yazılı kaynaklardan kullandığını, iki eser arasında büyük farklar bulunduğunu ifade etti. Son olarak XVII. yüzyılda ise Ebu'l Gazi Bahdır Han'ın "Şecere-i Terâkime" adlı kitabında bulundu. Reşideddin tarafından kaleme alınan Farsça varyantını Zeki Velidî Togan Türkçeye aktarmış, tarihî ve coğrafi bakımdan değerlendirdi. ${ }^{8}$ Nihad Sami Banarlı, "Resimli Türk Edebiyatı"" isimli eserinde son kısmı eksik olan Uygurca varyantını günümüz Türkçesine çevirdi. Bahaeddin Ögel, "Türk Mitolojisi”" ${ }^{10}$ başlıklı eserinde Uygurca ve Farsça varyantlarından yararlandı.

\footnotetext{
${ }^{1}$ Makalede "atlı göçerevli” terimi kullanılacaktır. Atlı göçerevli terimi, başıboşluktan ziyade bir aileye, bir topluluğa ve bir yurda bağlılığı gösterdiği için bu kavram tercih edilmiştir. İbrahim Kafesoğlu, Bahaeddin Ögel gibi önemli Türk kültür tarihi araştırmacıları, Türklerin yaşadıkları sahadan dolayı "Bozkır Kültürü", "Atlı göçerevli kültür” olarak tanımlamalarından ve at / koyunun hayatlarında belirleyici unsur olarak görülmesinden dolayı makalede "atlı göçerevli” terimi kullanıldı. Atlı göçerevli kültür, Türk medeniyetinin temeli olduğu gibi diğer medeniyetlere üstünlük sağlama da etkili oldu.

${ }^{2}$ Mübahat S. Kütükoğlu, Tarih Araştırmalarında Usûl, Türk Tarih Kurumu Yayınları, 2. Basım, Ankara 2017, s. 20.

${ }^{3}$ Muharrem Ergin, Dede Korkut Kitabı, Millî Eğitim Bakanlığı Yayınevi, İstanbul 1971, s. 5.

${ }^{4}$ Bahaeddin Ögel, Türk Mitolojisi, Türk Tarih Kurumu Yayınları, C. 1, Ankara 2010, s. V.

${ }^{5}$ M. Öcal Oğuz, "Destan Tanımı ve Eski Türk Destanları”, Milli Folklor Dergisi, Y.16, S. 62, Ankara 2004, s. 5.

${ }^{6}$ Ziya Gökalp, Türk Medeniyet Tarihi, Haz. İsmail Aka, Kazım Yaşar Kopraman, Kültür Bakanlığı Yayınevi, İstanbul, 1976, s. 90.

${ }^{7}$ M. Fuad Köprülü, Türk Edebiyat Tarihi, Ötüken Yayınları, İstanbul 1980, s. 41.

${ }^{8}$ Mehmet Kaplan, “Oğuz Kağan- Oğuz Han Destanı”, Türkler Ansiklopedisi, C. 3, Yeni Türkiye Yayınları, Ankara 2003 , s. 511.

${ }^{9}$ Nihad Sami, Resimli Türk Edebiyatı Tarihi, Milli Eğitim Basımevi, C. 1, İstanbul 1983, s. 17-21.

${ }^{10}$ Bahaeddin Ögel, Türk Mitolojisi, Türk Tarih Kurumu Yayınları, C. 1, Ankara 2010. 


\section{OĞUZ KAĞAN DESTANI'NDA İSKÂN: YAYLAK VE KIŞLAKLAR}

Oğuz Kağan Destanı'nın kaynak olarak değerlendirilmesi, birden fazla yazılı varyantının olması ve bu varyantlarda bazı farklılıkları beraberinde getirmiş̧tir. Belli dönemlerin karakteristik özellikleri, belli siyasi yapılar içinde kazandığı özellikler olsa da kültürün ve önemli yaşam unsurlarının süreklilik çizgileriyle ortak karakterler gösterdiği gerçektir. Bu anlamda, Uygurca Oğuz Kağan Destanı ile Farsça Oğuz Kağan Destanı arasında farklar ise şu şekildedir:

a) Uygurca metinde Oğuz Kağan, Tanrı elçisi olarak semavi bir bozkurtla konuşup onun kılavuzluğunda hareket etti. Kurt, Tanrı yurdunu koruyan, gökte yaşayan bir kurt değil; sadece Oğuz Kağan'a yol gösteren kutsal hayvandan söz edildi; ancak İslami Oğuz Kağan Destan'ında bozkurt'a rastlanmadı. ${ }^{11}$

b) İslami Oğuz Kağan destanında, Oğuz Kağan Çin, Hindistan, İran, Azerbaycan, Irak, Suriye, Mısır, Anadolu, Rus ve Frank ülkelerini fethettiğini anlatırken Hun, Kök-Türk ve Selçuklu devirlerini, hatta Osmanlı devletini kapsadı. ${ }^{12}$ Ancak Uygurca metinde sadece Urum (Roma), Hint, Tangut (Tibet), Mısır ülkeleri geçti.

c) İslami Oğuz Kağan destanında, Kur'an-ı Kerim'den ayetler, hadisler, İran edebiyatından örnekler bulunurken Uygurca metinde bu tür örneklere rastlanmadı.

d) Uygurca metinde, İslami dönem izlerine rastlanmadı, ancak burada da Oğuz 'un babası Ay Kağan olarak adlandırıldı. İslami dönem anlatışlarına göre ise Kara Han'dı. Bu nüshada babasıyla mücadele söz konusudur, Uygurca metinde böyle bir mücadele görülmez. Diğer taraftan, Uygurlar M.S.763'ten itibaren Mani dinine girdiler. Eski Türk dininde ise; gök ve güneş önemli bir yer tutmaktadır. Uygurlar Mani dinini kabul ettiği için ay birinci sıraya geçmiştir. Uygurca Oğuz Kağan Destanı'nda "Bir gün Ay Kağan'ın Gözleri aydın oldu" diye söze başlar; Türklerin bildikleri Tek bir Ay Han vardır o da Oğuz Kağan'ın ilk eşinden olan ikinci oğlu Ay Han'dır. Türkler Tanrıya "Gök Tanrı” derken Manihaizm 'e giren Uygurlar, Ay Tanrı demişlerdi. ${ }^{13}$

e) Uygurlar, Oğuz Kağan Destanı'nın esas konusuna dokunmadı, planını değiştirmedi, bu milli ananeden ayrılmadı. İslami dönem Oğuz Kağan Destan'ı ise Cengiz Han'dan sonra yazıldı, Cengiz devrinden kalma terimler de kullanıldı.

f) İslami Oğuz Kağan Destanı'nda, destan Türklerin atası Hz. Nuh'un oğlu Yafes'e bağlanmak suretiyle başlarken Uygurca metinde başlangıç noktası kayıptır.

g) İslami Oğuz Kağan Destanı’nda Oğuz Kağan babasının isteği üzerine amca kızlarıyla evlendirildi. Exogami (dıştan evlilik) yasasına aykırı olan bu rivayetin İslam devrinde girdiğine şüphe yoktur. ${ }^{14}$ Uygurca metinde gökten inen ve ağaç kovuğundan olan bir kızla evlendirildi.

Oğuz Kağan Destanı'nın her iki varyantında farklılıklar bulunsa da günümüze kadar yapılan araştırma ve tetkikler sonucunda çok geniş sahalarda yaşayan ve tarihlerinde muhtelif destan devirlerini geçiren Türklerin umumi destanı olduğu kesindir. Türklerin yaşadıkları coğrafi sahalar ve geçirdikleri çeşitli destan devirleri ve o devirlerde ortaya çıkan birçok destana, destan parçalarına ya da destan kalıntısına nadiren halk şiirlerinde rastlamakla birlikte tarihi metinlerde de görüldü. ${ }^{15}$ Türk edebiyatının önemli bir bölümünü oluşturan İslamiyet öncesi Türk destanları, Türklerin İslam dinine girmeden ve yerleşik hayata geçmeden evvel yaşadıkları atlı göçerevli kültürün özelliklerini taşımaktadır. Oğuz Kağan Destanı da, Türklerin içinde yaşadığı atlı göçerevli kültürün bir yansımasıydı. Kültür tarihçisi O. Menghin, Ural-Altay kavimlerinin sahip oldukları atlı göçebe kültürün, dünya medeniyetine ekonomik alanda hayvan yetiştirmeyi geliştirmede mahir olduklarını, toplumsal alanda devlet kurma kabiliyetleri olduğunu söyledi. Bunun yanı sıra, dünyanın başka coğrafyalarında güçlü ve sürekli devlet kurulmuş olsa da orada muhakkak hayvan yetiştiren unsurlar görüldü, bu kültürlerin kökü araştırıldığında ise Ural-Altaylı kavimlerin tesirleri olduğu anlaşıldı. Atlı göçerevli boyların yaşamı ve kültürleri üzerinde fikir belirten Koppers ise hayvan yetiştiren kültürün İç Asya'da doğduğunu, İndo-Germen kavimlerin bu kültürün yaratıcısı olmadığını, ancak ilk alıcısı olduklarını ifade etti. Son araştırmalarla bu kültürü ortaya çıkaranların Proto-Türkler olduğu da kanıtlandı. ${ }^{16}$ Bozkır kültürü içinde atlı göçerevli yaşamın dünya medeniyetine katkıları değerlendirmelidir. Bu konuda göçebeler olarak görülen Türklerin, sadece yüksek kültür inşasında bulunmadığı diğer devlet ve kültürlerin sınırlarında (Çin, İran, İslam Dünyası, Orta Çağ Slavları, Avrupalılar) yaşayarak onların kültürlerine yeni özellikler kazandırdıkları da bir gerçektir. Türkleri göçebe

\footnotetext{
${ }^{11}$ Fuzuli Bayat, “Oğuz Kağan Destanı Üzerine Yeni Düşünceler”, Türkler Ansiklopedisi, C. 4, Yeni Türkiye Yayınları, Ankara 2002 , s. 523.

${ }^{12}$ Osman Turan, Türk Cihan Hâkimiyeti Mefkûresi, Ötüken Yayınları, Ankara 2014, s. 146.

${ }^{13}$ Ögel, age, s. 130.; Osman Karatay, İlk Oğuzlar, Köken, Türeyiş ve Erken Tarihi Üzerine Çalışmalar, Ötüken Yayınları, İstanbul 2017, s. 34.

${ }^{14}$ Zeki Velidi Togan, Oğuz Destanı-Reşideddin Oğuznamesi, Tercüme ve Tahlili, Enderun Yayınları, İstanbul, 1982, s. 18; Abdulkadir İnan,

“Türk Düğünlerinde Exogamie İzleri”, Makaleler ve İncelemeler, Türk Tarih Kurumu Basımevi, Ankara 1968, s. 342.

${ }^{15}$ Gökalp, age, s. 42.

${ }^{16}$ Laszlo Rasonyi, Tarihte Türklük, Türk Kültürünü Araștırma Enstitüsü Yayınları, Ankara 1993, s. 4-5.
} 
olarak gördükleri için olumsuz çağrışımlarla tanımlayan yerleşik halklara rağmen, Türklerin sadece siyasi ve askerî alanda değil kültür ve üretim alanında da katkı yaptıkları görülmüştür. ${ }^{17}$

Atlı göçerevli kültürde yer alan bozkır toplum teşkilatında ailelerin ve boyların belli bir araziye kendi mülkü ve yurtları olarak baktıkları ve burayı herhangi bir boy veya düşman devletin işgal etmesine tahammüllerinin olmadığı ve barışçı düzenin bozulmamasına dikkat edildiği görüldü. Yaylak ve kışlakların aileler ve boylar arasında paylaştırıldığı (ülüşleştirildiği), devlet merkeziyetçiliğini belirleyen unsur olarak atlı göçerevli boylar arasında yaylak-kışlak bölgelerin belirlenmesi önemliydi. Atlı göçerevli yaşam ve iklimsel özellikler göz önüne alındığında yaylak ve kışlakların (orda) varlığıyla yaşam belirli zaman ve belirli yerler arasında gerçekleşti. Mevsimlik göçler, düzenli, doğrusal bir hat üzerinde kuzey ve güney doğrultusundaydı. Göç güzergâhları oldukça sabit, mevsimlere göre geçilecek otlaklar belirli ve öncelikli ihtiyaç yazın su, kışın ise hayvanların yiyecek tedarikiydi. Bu ihtiyaçlar, konaklanan yerlerde kalış süreleri, göçün yönü ve sıklı̆̆ı, göç mesafesine göre belirlendi. Herhangi bir savaş veya yenilgi olmadığı takdirde bu yaylak ve kışlaklar birbirinden ayrılmadı. ${ }^{18}$ Teşkilat ve düzene sahip bir topluluğun başıboş ve serserice gezmesi de mümkün değildi. Bu mevsimlik göçler, belirli bölgeler (yaylak- kışlaklar) arasında gerçekleşti ve yeni yurtların paylaştırılması da karmaşıklığın ve çatışmanın oluşmasını engelledi.

Atlı göçerevli kültürünün gelişme nedenlerinden en önemlisi ve genel karakteristik özelliği, yazların sıcak ve kurak, kışların ise aşırı soğuk geçtiği bozkır iklimidir. Bu iklim tipi tarımın gelişmesine elverişli olmadığı için hayvancılığın yapılmasına ve hayvancılığın gelişmesi sebebiyle de otlaklara ihtiyaç duyuldu. Bu ihtiyaçlar sonucunda yazın serin bölgelere, kışın ise daha ılıman bölgelere mevsimlik göçler meydana geldi. Türklerin hayat felsefesinde yaylak ve kışlak hayatı bu şekilde oluştu. ${ }^{19}$ Hayvanlar için ilkbahar ve sonbahar mevsimleri hemen hemen her bölgede beslenme açısından uygundu, ancak yazın ve kışın beslenmede yaşam koşullarının çok iyi belirlenmesi gerekti. Bu şartlar uygun olmadığı takdirde insan yaşamlarının son bulması ve yaşamlarının bağlı olduğu hayvanların telef olma tehlikesiyle karşı karşıyaydı. Yaylak ve kışlak hayatı, besinlere ve kuraklık veya zorlu iklimsel şartlara göre belirlendi. Atl1- göçerevli Türklerin besin kaynağı, süt ve süt ürünleri, et olmakla birlikte tahıl da önemliydi. Bacon'un dediği gibi et ve süt ürünleri ile sınırsız süre yaşayabilirler tanımlaması da eksiktir, çünkü yaylak ve kışlaklarda Türklerin tahıl ve bitkiler de tüketebilecekleri yerler olmalıydı. Kışlaklar, soğuk ve rüzgârlardan korunan, ağaç ve meraların bulunduğu, karın az yağdığı yerlerdi. Yazın ise göl ve nehirlerin bulunduğu sulak, haşarattan korunmuş açık alanlar olmasına dikkat edildi. Bunun yanı sıra, kışlak ve yaylaklar arasındaki göç yolu yüzlerce kilometreye uzanabilmekteydi. ${ }^{20}$

Atlı göçerevli kültürde at mühim bir yer tutmaktadır. Önemli kültür tarihçilerinden W. Schmidt, O. Menghin, W. Koppers, F. Flor ve W. Koppers Türklerin atı ehlileştiren ve hayvanların evcilleştirilmesinde önemli rol oynayan ilk topluluk olduğunu vurguladılar. ${ }^{21}$ Öyle ki Türk biniciler atlarıyla adeta tek vücut hâlindeydi, at üstünde görenler onların atın üstünde doğup orada yaşadıklarını düşündü. ${ }^{22}$ Bozkırda yükselti farklılıkları fazla olduğu için bölgeler arasında sıcaklık farkları bulunmaktadır. Dolayısıyla otlaklar her bölgede farklı zamanlarda yeşermektedir. Bu nedenle bozkır kültüründe hayvan sürülerinin beslenebilmesi için yer değiştirmek icap etti. At, hızlı yer değiştirme ve meraların önceden seçilmesi, aynı zamanda yarı vahşi hayvanlarının gerekli müdafaası, bir arada tutulması ve süratle hareket etmek gibi durumlar açısından büyük ölçüde çobanlıkla bağlantılıydı. Atlı göçerevli kültürünün bir diğer önemli unsuru da geçim kaynağı olarak koyundu. Bu koyun sürülerinin beslenmesi, güvenliği, bir arada tutulması gibi işler aile arasında ve boy sistemi içinde birlik oluşturdu. At ve koyun sürülerinin bir arada tutulması, otlakların tayini ve müdafaası, bedenî faaliyetten ziyade akıl gücü ve beceri gerektirdi; bu durum Türk insanına idare, emretme ve hâkimiyet gücü verdi. $^{23}$ At ve koyun sayesinde şekillenen yaşam tarzları ve geniş kitlelerin hâkimiyet altına alınması, merkeziyetçi devlet anlayışında geniş bozkırları teşkilatlandırmayı ve düzeni de beraberinde getirdi.

Türk düşünce yapısı, kültür ve geleneği, sosyal yapısı, coğrafi şartlar, çevresel etkenler, başka devletlerle siyasi ilişkiler gibi pek çok değişkenden etkilenerek şekillendi. Oğuz Kağan Destan'ında da Türk'ün yaşam biçiminin bozkır kültürü çerçevesinde atlı göçerevli yaşam tarzından şekillendiği görülmektedir. Bu çerçevede Oğuz Kağan'ın temel hedefi, dünya hâkimiyetini sağlamaktı. Oğuz Kağan hâkimiyetini kabul etmek istemeyen

\footnotetext{
${ }^{17}$ Michal Biran, "Nomads as Agents Of Culturel Change”, The Mongols and Eurasians Predecessors Nomadic Culture, Edited By. Reuven Amitai, Michal Biran, University of Hawai’i Press, Honolulu, 2015, s. 1-2.

${ }^{18}$ Emel Esin, İslamiyet'ten Önceki Türk Kültür Tarihi ve İslam'a Giriş, Edebiyat Fakültesi Matbaas1, İstanbul 1978, s. 112.; Anatoly M., Khazanov, Göçebe ve Dış Dünya, çev. Ömer Suveren, Doğu Kütüphanesi Yayınları, İstanbul 2015, s. 138-139.

${ }^{19}$ İlhami Durmuş, "Türk Kültür Çevresinde Kültür Adlandırmaları”, Gazi Akademik Bakış Dergisi, C. 8, S. 15, 2014 , s. 272.

${ }^{20}$ Rasonyi, age, s. 49-50.; Nikolai N. Kradin, Nomadism, Evolution and World -System: Pastoral Societies in Theories of Historical Development, Journal of World Systems Research, 8, (3), 2002, s.369-370.; Khazanov, age, s. 141.

${ }^{21}$ İbrahim Kafesoğlu, Türk Milli Kültürü, Ötüken Neşriyat Yayınları, İstanbul 1998, s. 220.

22 Jean Paul Roux, Türklerin Tarihi: Pasifik'ten Akdeniz'e 2000 Yll, çev. Aykut Kazancıgil, Lale Arslan Özcan, Kabalcı Yayınları, İstanbul 2017, s. 55.

${ }^{23}$ Jozsef Deer, “İstep Kültür”, çev. Şerif Baştav, Ankara Üniversitesi Dil ve Tarih-Coğrafya Fakültesi Dergisi, C. 12, S. 1-2, 1954, s. 160161 .
} 


\section{OĞUZ KAĞAN DESTANI'NDA İSKÂN: YAYLAK VE KIŞLAKLAR}

kavimler ve devletler üzerine sefere çıktı. Oğuz Kağan bu idealini gerçekleştirirken Türk yaşam biçimi olan atlı göçerevli kültürden de uzaklaşmadı. Gittikleri sahalarda, boyların yaşamlarına uygun olan bölgeleri yaylak ve kışlaklar olarak belirledi. Oğuz Kağan'ın yaylak ve kışlak olarak belirlediği sahalar, su kaynakları bol olan ve hayvanlarını otlatabilecekleri yerler oldu. Yine bu bölgeler, dışarıdan gelebilecek saldırılara karşı kendilerini koruyabilecekleri bölgelerde kuruldu. İklimi ve coğrafi şartları yaşam şekillerine uygun yaylak ve kışlaklar savunma ve saldırılara karşı korunaklı yerlerdi.

\section{Türklerde Göçebelik ve Atlı Göçerevli Meselesi}

Göçebe terimi, dünyadaki çeşitli toplumları tanımlamak için batılı araştırmacılar tarafından kullanıldı. Barbar kelimesiyle özdeş kullanılan göçebe teriminin birinci ölçütü, yerleşiklik noktasında tarıma geçmemek, böylece yerleşik uygarlığa yabancı kalmak, ikinci ölçütü ise yerleşik uygarlıklara yapılan saldırılardı. Böylece, yerleşik hayata geçmeyen, yerleşik toplumlara sürekli saldırılar yaparak onların tarlalarına zarar veren topluluklar göçebe / barbar olarak nitelendirildi. ${ }^{24}$

Göçebe kelimesinin terim tanımlaması birçok şekilde yapıldı; bu tanımlamalar mesela Türk Dil Kurumunun Türkçe Sözlük'ünde, Farklı şartlara bağlı olarak belli bir bölge içerisinde çadır, hayvan ve diğer araç - gereçlerle yer değiştiren, yerleşik olmayan, göçer ve göçkün kimselerdi. Bahaeddin Ögel, Farsça "göçave" kavramının Türk dilinde "göç-oba" kelimesinden gelir diyerek bu kavramı Hayvancılığa, otlak sahalara bağll yllın belirli dönemlerinde yer değiş̧tirenler için kullanıldığını vurguladı. ${ }^{25}$ İsmet Zeki Eyüpoğlu'nun Türk Dilinin Etimoloji Sözlügü̈"nde, "köçer-oba"dan türediğini, köçer oba, köçebe /göçebe olarak belirtti. Tuncer Baykara ise Göçebelerin bir yerde karar kllmaksızın hem zaman hem de mekânda hareket eden kimse, gruplardı. Tarama Sözlük’ünde "göçer" kelimesi Gezer, bir yerde durmaz, göçebe olarak açıklandı. ${ }^{26}$ Sosyoloji Sözlük'ünde ise Geçim araçlarını elde etmek için mevsimlere göre yaylak ve kuşlak değiş̧tiren, toprağa yerleşmemiş olan toplumların hayat tarzldır. Avcllik, hayvan yetiştirme, çiftçilikle geçinen boy halindeki kavimler, esasta göçebedirler. Göçebeler, otlaklara ulaşmak ve bereketli bölgelere topluluklar halinde yer değiştirir ve akınlar gerçekleştirirler, şeklindeydi. ${ }^{27}$ Tuncer Gülensoy'un Etimolojik Sözlük’ünde Göç- köç- + göçme'den türemiş, Anadolu ağızlarında, göçer, göçme, köşpe şeklinde geçerken Türk Dünyasında köçeri (Az.), küsme xalık (Başk.), köşpeli (Kazak); köçmön, köçamal, (Kırgız); köçmançi (Özb.); küçme xalık (TatK.); köçman (Uygur); göçmen (Türkm.); Doefer'da köç-oba şeklinde geçtiğini ifade etti. ${ }^{28}$ Göçebe tanımı, göçebe yaşamlarla tam örtüş̧mediği gibi eksik ve hatta hatalı da kullanıldı. Önemli araştırmacılardan Anatoly M. Khazanov, haytalarını tüketime dayalı idame ettiren Türkler için "pastoral göçebe" terimini kullandı ve hayvan sürülerine sahip çobanların yaşamında bir üretimin söz konusu olduğunu ifade etti. Araştırmacı, sürekli gezerek ve arayarak hayatını devam ettiren, doğada buldukları ile beslenen, buna uygun bir kültür oluşturan avcı-toplayıcilarla, hayvan sürüleri için yılın belli dönemlerini belirli yerlerde geçiren pastoral göçebeler ile bir amacı olmaksızın gezen gezgin (wandering) gruplar için göçebe terimini kullanır. ${ }^{29}$ Çeşitli araştırmacılar tarafından farklı ifade edilmesine rağmen göçebelikte iki ana husus üzerinde durulmaktadır: Araştırmacıların bir kısmı göçebeleri iktisadi yapılarından bağımsız şekilde ele alıp onların gezgin bir hayat sürdüklerini; bir kısmı ise tarım ile çok az uğraşan veya hiç uğraşmayan gezgin kavimleri göç merkezli bir hayat tarzından ayırmak amacıyla pastoral nomadizm terimini tercih ettiler. Khazanov, bütün gezgin pastoralistlerin de göçebe kavramı içine konduğunda sınıflamanın ve tanımın tam olmayacağını vurgularken pastoral göçebeliğin açıklamasını geçim kaynaklarının karakteristik özelliklerine göre yaptı. Pastoral yaşamın ilkel karakterini, hayvancıllkta otlakların yıl boyunca açık alanda yapılmasına ve bir kapalı alan (ahır) bulunmamasını göçebeliğe bağladı. Belirli otlaklar arasında mevsimsel yer değiştirmeler topluca gerçekleştiği ve hayvanlarla birlikte göç edildiği için pastoral göçebe terimini kulland. ${ }^{30} \mathrm{Bu}$ özelliklerle aslında, Khazanaov göçebelik içinde tanımladığı pastoralistlerin farklı özelliklere sahip olduğunu da ifade etti.

Türklerin yaşam tarzlarından dolayı yapılan tanımlamalardan biri, yarı yerleşik pastoralizmdi. Bu türü yarı göçebe pastoralizmden ayıran en temel özellik geçim kaynağının hayvancılıktan ziyade tarıma dayanmasıydı. Yarı yerleşik pastoralist topluluklar, mevsimlik göçleri aileleriyle birlikte yapmasıydı. Bu göçler, genellikle aynı coğrafi bölgede yaşayan göçebe toplulukların göçlerine nazaran daha kısa mesafeli ve daha kısa süreliydi. Zeki Velidi Togan da İbrahim Kafesoğlu gibi Türklerde göçebelik meselesi için onların tam göçebe olmadıklarını yaylak ve kışlaklarda hayat sürdüklerini dile getirdi. Mesela, Asya Hunlarından itibaren Isık Gölü ve

\footnotetext{
${ }^{24}$ Baykan Sezer, Asya Tarihinde Su Boyu Ovalarl ve Bozkır Uygarlıkları, Edebiyat Fakültesi Basımevi, İstanbul 1979, s. 82.

${ }^{25}$ Bahaeddin Ögel, Türk Kültür Tarihine Giriş I., Kültür ve Turizm Bakanlığı Yayınları, Ankara 1978, s. 5.

${ }^{26}$ Anıl Yılmaz ve Cahit Telci, “Türk Kültür Terminolojisinde Göç Kavramı Üzerine”, Modern Türklük Araştırmaları Dergisi, C.7, S. 2, 2010, s. 15-16.

${ }^{27}$ Hilmi Ziya Ülken, Sosyoloji Sözlüğü, Milli Eğitim Basımevi, İstanbul 1969, s. 119.

${ }^{28}$ Tuncer Gülensoy, Türkiye Türkçesindeki Türkçe Sözcüklerin Köken Bilgisi Sözlüğ̈̈, Türk Dil Kurumu Yayınları, C. 1, Ankara 2007, s. 374.

${ }^{29}$ Khazanov, age, s. 93-94.

${ }^{30}$ Khazanov, age, s. 93-95.
} 
Karakum'da kışlaklar bulundu. Asya Hunları, dinî ve siyasi birçok toplantının yapıldığı Şansi bölgesinde ve Orhun havalisinde yaylak yerlerine sahiptiler. Göktürklerin ise kış aylarında köy ve şehirlerde kalırlar yaz ayları gelince Tiyanşan (Tanrı) Dağları'nın yüksek yerlerine çıkıp yayladıkları bilinmektedir. Yine Batı Göktürklerin önemli yaylak yeri Talas şehrinin batınında bulunan Bingöl yöresi, İstemi Yabgu'nun bulunduğu ve Oğuz Kağan Destan'ında geçen önemli bir dağ olan Ak Dağ, İli nehri üzerindeki Kong-Yue şehri gibi birçok yer Türkler tarafından yurt edinildi ve yaylak olarak kullanıldı. Emel Esin ise Beşbalık şehrinin, Uygur Kağanlığı’nın yaylak (yazlık) başkenti olduğunu ifade etti. Türklerin Ötüken, Isık Gölü ve çevresi, Barsagan bölgesi ve Talas bölgesi gibi yerlerde kışlakları bulunmaktadır. ${ }^{31}$ Türkistan'da yaşayan Karakalpaklar diğer Türk toplulukları gibi kışları "aul"larda yaşarlar, yaz geldiğinde yaylak / otlak alanlara göç ederler, "yurt" adı verdikleri otağ / çadırlarda yaşarlardı. Bu otlaklar aullara çok yakın, birkaç yüz metre uzaklıkta olabiliir ${ }^{32}$ örneğiyle de konargöçer / atlı göçerevli Türkler tanımlaması uygundu.

İnsanoğlunun iklim, tabiat ve coğrafya ile mücadele etme noktasında yetersiz kaldığı dönemlerde farklı yaşam tarzlarını belirlediği bir gerçekti. Kadim dönemlerde, insanların verimli topraklarda ve suyun bol olduğu bölgelerde çiftçilik; bozkır alanlarında bol otlakların bulunduğu bölgelerde hayvancıllk, ormanların bulunduğu daha yüksek rakımlı yerlerde ise avcllk ve toplayıcllı yaparak hayatlarını idame ettirdikleri görüldü. İnsanların yaşam serüvenini iklim, tabiat ve coğrafya belirledi. Bu dönemde, orman kavimleri, asalak kültürüne bağlı avcılık, devşiricilik; tarım bölgelerinde yerlerde oturanlar köylü kültürüne bağlı çiftçilik; bozkırdakiler ise çoban kültürüne bağlı besicilikle uğraştı. ${ }^{33}$ Türkler, Türkistan coğrafyasının iklimsel yapısından ve coğrafi özelliklerinden dolayı kendilerine has bir kültür / medeniyet meydana getirdi. Bu sebeple kültürleri farklı şekillerde tanımlandı. "Türklerin yaşadıkları coğrafyaya bağlı "bozkır kültürü", koyun ve at sürülerini hem evcilleştirmeleri hem de otlatmalarından dolayı "çoban kültürü", bölgeler arasında hareketli yaşam tazından dolayı "konargöçer kültür" çerçevesinde tanımlandı. Günlük yaşamlarında atı kullanarak hızla uzak bölgelere gidebilmelerinden dolayı "atlı kültür", başıboş göçmedikleri ve yaşadıkları çadır / otağ evlerden, aileleriyle göç ettiklerinden "atlı göçerevli kültür" ve yazılı dönem öncesi kültürlerini aydınlatan kurganlardan çıkarılan buluntular nedeniyle de "kurgan kültürü"nün temsilcileri” olarak görüldü. ${ }^{34}$

Yakın döneme kadar Kazakların, yaylak ve kışlak hayat yaşadığı varsayıldığında, yazın yaylaya çıkmakla birlikte kışın kerpiçten yapılmış evlerde (kışlak) oturdu. Mesela Aşağı Sırderya boylarında, Çimkent, Evliya-Ata, Pişmek'de "yatak" lar (Kazak ve Kırgızcada catag) göç taşıyacak hayvanları olmadığında göç etmeyerek kışlaklarda kalan göçebeler vardı. ${ }^{35}$ Sergei Grigoreviç Aganacov'dan aktarılan ve Oğuz Kağan'a atfedilen "Hep hareket edin, yerleşik olmayın, bahar, yaz veya kış otlaklarında, topraklarda dolaşın; başka bir şey istemeyin. Süt, yoğurt ve kirmanlarınızın (deve ve kısrak sütünün karıştırılmasıyla oluşan içeçek) azalmasına izin vermeyin.” sözleri ile atlı göçerevli yaşamın Oğuz Kağan / devlet tarafından desteklendiği görüldü. ${ }^{36}$

\subsection{Türk Kültüründe Yaylak -Kışlaklar}

Türkler çok geniş alanlar ve coğrafyalarda yaşayan bir millettir. Bu coğrafyada iklim şartları, yer şekilleri, su kaynakları, otlaklar ve toprak göz önüne alındığında Türkler yaşadıkları coğrafyayı genişletti ancak zaruri bir durum olmadığı sürece yaşadığı yerleri terk etmedi. Ayrıca Türkün hayatında hayvan beslemek esas olduğundan yaylak ve kışlaklara bağlı bir hareketlilik görüldü. Türkistan coğrafyası hem iklimsel özellikler hem de geniş arazileri ve coğrafyasıyla yaylak ve kışlak alanlar için uygundu. İklimsel özellikleri, yazların sıcak ve kurak, kışların ise sert ve rüzgârlı geçmesinden yaşamsal alanları özellikle yaz ve kış aylarında doğru belirlemek de gerekliydi. Bu sebeple kışlak seçilen mekânlar hayvanları kışın sertliğinden korumalı, yani ormanlık veya derin vadi olmalı, aynı zamanda bol su ve odun bulunmalı, otlaklar kar altında kalmamalıydı. Yaylaklar ise göl ve akarsu boylarında, hayvanların haşarattan korunduğu açık ve düz araziler olmalıydı. ${ }^{37}$ Yaylak ve kışlak, Türklerin yaşamlarında vazgeçilmez iki unsurdu. Boylar, bir düzen içinde yazın belirli yerlerde yaylanırken kış aylarına gelindiğinde yine belirli yerlerde kışladı. ${ }^{38}$ Yaylağa çıkma zamanı geldiğinde halk boy beyinin emriyle hareket ederdi. Nisan ayları yaylağa çıkmak için en uygun zamand1. ${ }^{39}$ Belirli mevsimlere bağlı olan bu hareketlilik yılın belirli zamanlarında yapıldı. Bu mevsimlerin isimleri; yaylak (yaz), yazlak (ilkbahar), kışlak

\footnotetext{
${ }^{31}$ Zeki Velidî Togan, Umumî Türk Tarihine Giriş, Enderun Kitapevi, İstanbul Üniversitesi Edebiyat Fakültesi Yayınları, İstanbul 1981, s. 107.; Özcan Kayalı, 8. ve 11. Yüzylllar Arasında Göçebe Türklerin Yaylak ve Kışlak Hayatı, Marmara Üniversitesi Türkiyat Araştırmaları Enstitüsü (Yayımlanmamı̧̧ Yüksek Lisans Tezi), İstanbul, 2010, s. 29.; Esin, age, s. 227; Kafesoğlu, age, s. 322.; Kayalı, agt, s. 50.

${ }^{32}$ Khazanov, age, s. 94- 102.

${ }^{33}$ Kafesoğlu, age, s. 213.

${ }^{34}$ Durmuş, agm, s. 271.

${ }^{35}$ Zeki Velidî Togan, Bugünkü Türk İli (Türkistan) ve Yakın Tarihi), C. 1, Güven Basımevleri, İstanbul 1942, s. 19.

${ }^{36}$ Khazanov, age, s. 179.

${ }^{37}$ Durmuş, agm, s. 272.

${ }^{38}$ Tuncer Baykara, "Göktürk Yazıtlarının Türk İskân (Yerleşme) Tarihindeki Yeri”, Türk Dili Araşstrmaları Yılllğgl- Belleten, C. 38, 1990, s. 24.

${ }^{39}$ Rasonyi, age, s. 49.

205

GTTAD, Cilt: 3, Sayı: 6, Temmuz 2021
} 


\section{OĞUZ KAĞAN DESTANI'NDA İSKÂN: YAYLAK VE KIŞLAKLAR}

(kış) ve güzlek (sonbahar)tir. Ancak yoğun hareketlilik daha çok yaz ve kış mevsimlerinde gerçekleşmekteydi ${ }^{40}$ Atlı göçerevliler, genelde kış otlaklarında dört-beş ay, yaz otlaklarında iki ay kadar kalıp, yılın geri kalan bölümünü bu iki bölge arasında göç ederek geçirirler. Otlak bölgelere gelindiğinde ayda bir veya üç defa mera değişikliği yapılır. Göç esnasında sürüler her gün hareket hâlinde olur, doğumlar dışında ara verilmez. ${ }^{41}$ Türklerin ancak yaz ve kış mevsimlerini geçirmek için yaşam tarzlarına ve iktisadi yapılarına uygun karar verdikleri yaşamlarını yaylak ve kışlaklarda belirli bölge ve zamanda geçirdikleri ortaya çıktı.

Türk göçlerinin sebeplerini yalnızca otlak ya da sulak alanlar olarak söylemek doğru olmaz. Göç sebepleri arasında, Türklerin bağımsızlık ruhu, başka bir milletin hâkimiyeti altında yaşamamak ya da boylar arasındaki mücadeleler de önemliydi. Kaynaklardan anlaşılacağı üzere Türklerin cihangirlik ülküsü gereği yayıldıkları coğrafi sahalar da çok geniştir. Bu geniş coğrafi sahanın batısında; Tuna, Tın, Yayık kıyıları, Aral Gölünden Isık Gölüne, Tanrı Dağları'na, Kuzeyde Ertiş ve Yumar Vadileri, Altunyış Dağlar'ından Yenisey Vadisine, Kögmen Dağları'ndan Orhun vadisine, Baykal Gölü’nden Kingan Dağları'na, Ordos Yaylası'ndan Shantung Ovası'na kadar olan bölgelerinde yaylak ve kışlak bölgelerde Türk boylarının yaşadığı, doğusunda ise Göktürkler, Uygurlar ve Kırgızların yaşadıkları görüldü. ${ }^{42}$ Türk bozkır kültürünün ilk geliştiği bölge, Altay Sayan Dağları'nın güneybatı düzlüklerinde bol otlaklarıyla yaylaklardı. ${ }^{43}$ Çin kaynakları, Hunların yaylakları yitirdikleri için söyledikleri türküyü şöyle ifade etmektedir: Yen-çi shan Dă̆ını yitirdik, Kadınlarımızın güzelliğini aldılar. Si -Lan şan Yaylasını yitirdik. Hayvanlarımızı üretecek yeri aldılar. ${ }^{44}$

Göktürk Yazıtları’nda da kışlak terimi geçmektedir. Etimolojik olarak kışlamak fiilinden türediği görüldü. Bahaeddin Ögel bunu mevzu bahis ederken Kaşgarlı Mahmud'un “Öz Köz ir kışlag” atasözünü şöyle açıkladı: Kışlağın güney taraflarını alan bir adam ile ilgilidir. Çünkü kışlağın güney taraflarında uzun otlar bulunur ve oralar don olmaz pek kar düşmezdi. ${ }^{45}$ Divanü Lugat-it Türk’te de kışlamak sözcüğü şöyle geçmektedir: Er evinde kışladı (Adam evinde kışladı). ${ }^{46}$ Yaylak ise kışlağın tersi yani yazın oturulan çoğunlukla yüksek dağların tepeleriydi. Eski Türk dilinde söylenen Ol koyın yaylagda yazlattı ve ol yaylagda küzledi sözlerinden anlaşıldığına göre bahar aylarından sonbahara kadar devam eden zaman dilimini kapsadı. ${ }^{47}$ Bozkır kültürünün temsilcileri olarak yaşamlarını sürüleriyle birlikte geçiren Türkler, mevsimlere göre kışlak ve yaylaklarda otururlardı. Eski Türk metinlerinde bu iki kavram şöyle geçmektedir: Yırtıcı kartalım, yeşil kayalar yazın geçirdiğim, kızıl kayalar ise kışın geçirdiğim yerler... Bu iki kavram daha sonraki zamanlarda da temel anlamını korumaya devam etti. $^{48}$

Kışlak denilince akla yalnızca hayvanlarını otlatabilecekleri bir yer gelmemelidir. Kışlaklar, bazen ırmak, bazen bir köy bazen de bir şehir olabilmektedir. ${ }^{49}$ Yaylaklar ise yüksek dağlık kesimlerdi, büyük hayvan sürülerine sahip eski Türk devletlerinde her boya ikta olarak yaylak yeri verildi. Türk destanlarında da s1k sık geçen yurt bulmak, yurt ermek sözü buradan kaynaklanmaktadır. ${ }^{50}$ Kışlaklarda sert iklim koşullarını atlatmak için bir arada yaşama arzusu bulunmaktaydı. Bu sayede karşılarına çıkabilecek tehlikelere karşı birlikte hareket ederlerdi. Böylece Türk boyları arasındaki siyasi ve askerî bağ güçlenirdi. Göktürk Yazıtlar'ında Türklerin mücadele esaslarının ve savaş özelliklerinin yaylak hayatına göre belirlendiği, kış aylarında ise hayatın geri kalan zamanının geçirildiği söylendi. Kışlaklarda, coğrafyanın sert iklim koşullarına bağlı olarak yurtlarında rüzgârın devamlı estiği yönlere doğru taş ve toprakla korunaklı setler inşa ederlerdi. Ayrıca dışarıdan gelebilecek tehlikelere karşı han ya da hakanların otağının çevresi çitlerle korunurdu. ${ }^{51}$

Hayvancılıkla geçinen Türkler, her mevsim taze yeşil ot biten yaylaklarda hayvanlarını semirtirlerdi. ${ }^{52}$ Beslenmede önemli bir yer tutan hayvanların eti, ülüş adı verilen on iki parçaya ayrılırdı ve hayvan kesildiğinde etin belli yerleri belirli kişiler tarafından paylaştırılırdı. ${ }^{53} \mathrm{Bu}$ paylaştırma, ülüş, sadece siyasi hayatta değil toplum hayatında da insanların yerlerinin, konumlarının ve statülerinin, ikramlarda pay ve parçaya göre düzenlenmesi

\footnotetext{
${ }^{40}$ Baykara, agm, s. 21- 22.

${ }^{41}$ Ögel, Türk Kültür Tarihine Giriş, s. 10.; Khazanov, age, s. 129- 130.

${ }^{42}$ Esin, age, s. 85.

${ }^{43}$ Kafesoğlu, Türk Milli Kültürü, s. 212.

${ }^{44}$ Banarli, age, s. 45.

45 Ögel, age, s. 10.

${ }^{46}$ Kaşgarlı Mahmud, Divanü Lügat-it Türk Tercümesi, çev. Besim Atalay, C. III, Türk Dil Kurumu Yayınları, Ankara 1941, s. 299.

${ }^{47}$ Ögel, age, s. 23.

${ }^{48}$ Mesut Şen, "Türklerde Kışlag ve Yaylag Kavramları Üzerine Düşünceler”, Çukurova Üniversitesi Türkoloji Araştırmaları Dergisi, C. 3, S.

2, 2018, s. 134.

49 Ögel, age, s. 39.

${ }^{50}$ Ögel, age, s. 25.

${ }^{51}$ Baykara, agm, s. 22-23.

${ }^{52}$ Osman Gümüşçü, "Yaylak ve Kışlak", TDV İA, s. 669.

${ }^{53}$ İnan, "Orun ve Ülüş Meselesi”, Türk Hukuk ve İktisat Mecmuast, İstanbul 1931, s. 131.
} 
töre olarak görüldü. ${ }^{54}$ Yaylaklarda düzeni oluşturan bir olgu da orun meselesidir. Orun genel olarak yaylaya çıkıldığında ailelerin çadırlarını kurma nizamıdır. Hakanın çadırı merkezî korunaklı bir alanda kurulur ve etrafına belirli kurallar çerçevesinde diğer çadırlar dizilirdi. ${ }^{55}$

Kışlaktaki yemek kültürü göre et, en önemli besindi. Yaylaklarda kesilen hayvanların etleri çeşitli şekillerde muhafaza edildi. Örneğin bu etler hayvan bağırsağının içine konularak kış aylarına saklanırdı. Yine bu etlerden sucuk ya da pastırma yapılarak sonraki mevsime ayrılırdı. Kışlaklarda beslenmenin önemli bir bölümü süt ve süt ürünlerinden oluşurdu. Sütten; peynir, kaymak, yoğurt gibi ürünler yaparlardı. Ayrıca yukarıda belirtildiği gibi az da olsa buğday ekilir, buğdaydan üretilen içecek ugut yapılırdı. ${ }^{56}$ Yaylak ve kışlak hayatı mevsimsel düzenlendiği gibi beslenmeleri de mevsimsel düzenlenirdi. Kışlaklarda etler avlanılan hayvan eti ile evcil hayvanların etleri olmak üzere iki kısma ayrılmaktadır. Evcil hayvanların etinin büyük bir bölümü at ve koyun etinden oluşmaktadır. ${ }^{57}$ Bununla birlikte Bahaeddin Ögel, Oğuzların İslam'a girişiyle birlikte at etinin önemini kaybettiğini ve bunun yerini koyun etinin almaya başladığını söyler. Ancak birçok içecek olduğu hâlde at sütü (kımız) diğer içeceklere tercih edilirdi. ${ }^{58}$

\subsection{Oğuz Kağan Destanı’nda Yaylak ve Kışlaklar}

Milletlerin yaşayış, düşünüş ve inanışlarına bakıldığında milli destanlar birinci derecede ehemmiyet göstermektedirler. Destanlar yalnızca tarihin eksikliklerini doldurmakla kalmaz aynı zamanda toplumun sosyal yaşamlarını düşünüş ve inançlarını meydana getirir. ${ }^{59} \mathrm{Bu}$ hususta Türklerin bir cihan şümul devleti kurmasının ilk örneği Oğuz Kağan Destanı’nda açıkça görülür. Oğuz Kağan, Çin ve Hint bölgelerinden başlayarak Gur ülkesine daha sonra Doğu memleketlerini itaat altına almak üzere İdil Volga havzasına gelir oradan da Demir kapı üzerinden Kafkaslara ve Anadolu'ya ulaşır. Buradan İran ve Semerkant bölgelerini ele geçirir. ${ }^{60}$ Oğuz Kağan, vatan olarak kabul ettiği bu dağlarda cihangirlik seferine çıkarken hazırlık yapar, hayvanlarını semirtir, boylarının yaylak ve kışlak yerlerini belirler. ${ }^{61}$ Nitekim Oğuz Kağan ve halkı bu bölgeleri ele geçirdikten sonra yaylak ve kışlak alanlarda otağlarını kurdu. Destanda gösterildiği üzere, Türklerin ilk yurdu Or ve Kür Tag ${ }^{62}$, dır. Bu bölgeler Oğuz Kağan'ın dönüp dolaşıp geldiği kendi öz yaylaları, anayurdu oldu. Üçoklara ait yaylaları Kür Dağ'ının Almalıg bölgesine yakın bölgesi; Bahaeddin Ögel ve Andrey N. Kononov ise Or ve Kür Dağı'nın günümüzde Alma Ata bölgesindeki Çu havalisinde bulunabileceğini ifade ettiler. ${ }^{63}$

Oğuz Destanı’nda devletin merkezi, Balkaş Gölü ve Sırderya ırmağının kuzeyindeki Or Dağ ve Kür Dağları oluşturdu. Or ve Kür Dağlar yaylakları oluştururken kışlakları Borsuk Kum ile İle nehri, Taşkent'in kuzeyindeki Kazıkurt Dağ (kırk kapılı Sayram) ve çevresini, Semerkant'ı kapsadı. ${ }^{64}$ Destanda Türklerin ilk atası kabul edilen Abulca Han'ın yaylak ve kışlağı olarak Türkistan belirtilmektedir. Destanda sıkça bahsedilen Oğuzların kışlakları olarak ise Or ve Kür Dağlar'la aynı bölgede olan Karakurum'a yakın Borsuk ve Kakyan şehirleriydi. ${ }^{65}$ Yukarıda da belirtildiği gibi han ya da hakanın otağları yaylak ve kışlaklarda kuruldu ve bunların etrafı çitlerle çevrildi. $\mathrm{Bu}$ otağların yerlerinin yaylak ve kışlaklarda en yüksek ve korunaklı yerlerde inşa edilmesi ise güvenlik sebebiyleydi. ${ }^{66}$ Oğuz Kağan ana yurt olarak kabul ettiği yaylaklarda Or ve Kür Dağları'nda büyük bir toy vererek oğullarından Bozokları sağ tarafinda, Üçokları ise sol tarafina oturtarak onlara: Ey oğullarım! Çok savaştım; artık çok yaşlandım. Düş̧anları ağlattım; dostları sevindirdim. Gök-Tanrı'ya borcumu ödedim diyerek oğullarına yaylak ve kışlak yurtlarını paylaşıtırdığı görüldü. ${ }^{67}$

Yaylaklarda yaz aylarında savaşlar yapılırken kış aylarında kışlaklarda savaş hazırlıkları yapıldı. Nitekim Göktürkler, kışın uç kalelerinde kışlayarak yaz ayları geldiğinde Oğuzlara karşı harekete geçmişlerdi. ${ }^{68}$ Oğuz Kağan, Azerbaycan taraflarına gelirken o yıl yaylak olarak Tebriz'in güneyindeki Ucan yaylaları, Aladaglar, Sebelan Dağları'nı (Ağrıböri) belirledi, buraya Aladag ve Sebelan adını da verdi, bu yaylaklarda kaldıkları sürece ülkeleri ele geçirdi. Arran ve Mugan ovalarını kışlak yeri olarak belirledi. ${ }^{69}$ Arran ve Mugan bölgeleri

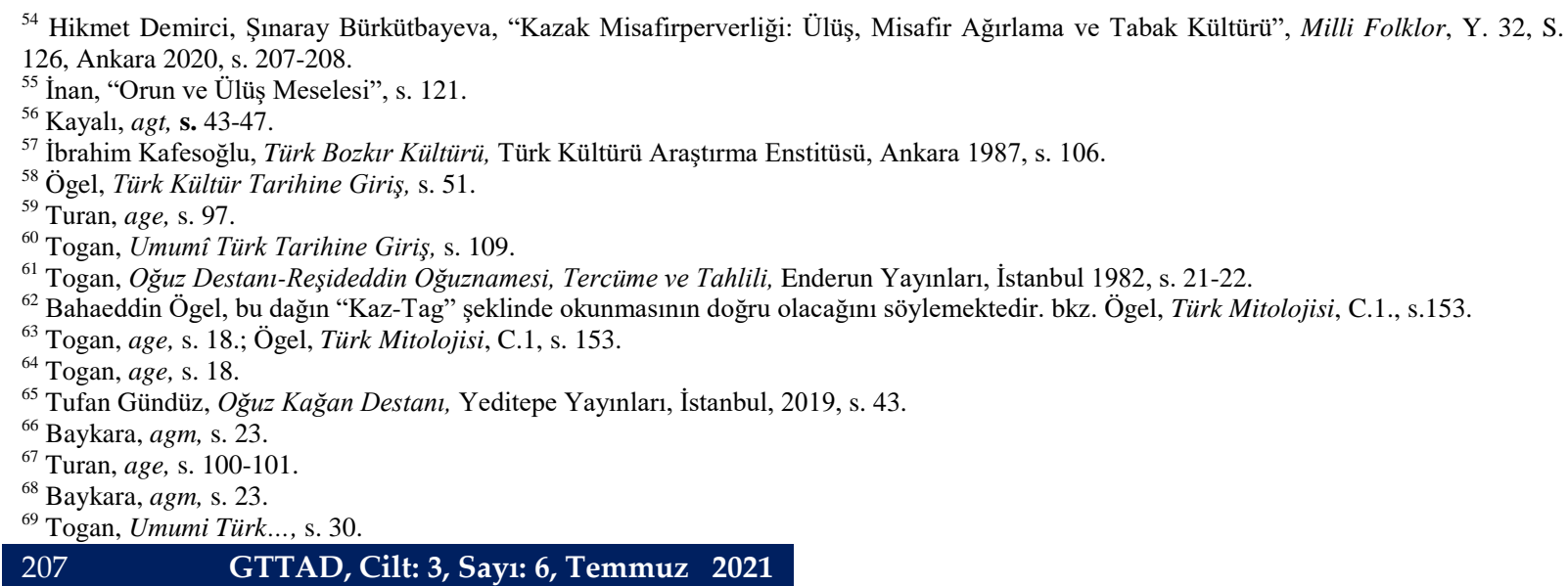




\section{OĞUZ KAĞAN DESTANI'NDA İSKÂN: YAYLAK VE KIŞLAKLAR}

Azerbaycan'ın Şirvan taraflarındadır. Oğuz buraya geldiğinde yaz mevsimiydi, Şirvan ülkesinin yakıcı güneşinde sefere çıkmak zor olduğu için bir araya gelerek yazlarını yaylalarda geçirmeye karar verdi. Yaylaklar, o vilayetteki Ağrıböri (Ağuri) ve Ala Dağları (Sebelan Dağları) varıncaya kadar bütün dağları aşıp buraları topraklarına kattı. ${ }^{70}$ Oğuz Kağan, Mazenderan'a giderek Amul, Sarı, Astrabad gibi şehirleri aldıktan sonra yazın Herat'a gelerek burayı yaylak yaptı. ${ }^{71}$ Dimaşk (Suriye) taraflarına gelince burayı il yaptıktan sonra Mısır'a doğru yol aldı. Oğuz Kağan buraya vardığında Kudüs ve Halil vilayetlerinde kışladı. Bundan sonra yaz aylarında Oğuz Kağan, Bağdat ve Basra taraflarına geldi, bu bölgeye geldiğinde yaz ayları olduğu için Baalbek Dağları'nı yaylak yaptı. ${ }^{72}$ Bundan sonraki zamanlarda Oğuz Kağan, Irak-1 Acem taraflarına gittiği yıl Demavend Dağı'na çıktı ve orayı yaylak yaptı. Oğuz Kağan tüm yazını buradaki yaylakta geçirdi. Yaz mevsimi sona erdiğinde Demavend'den hareket etmeye başladı ve bu bölgede bulunan diğer şehirleri alma niyetiyle yola çıktı. ${ }^{73}$ Oğuz Kağan'ın Demavend Dağı yüksekliği itibariyle ulu ve yüce bir dağ olarak gördü ve burayı da yaylak yaptı. Yukarıdaki örneklerden anlaşılacağı üzere, Oğuz Kağan, gittiği bölgelerde de yaylak ve kışlaklarını belirledi. Bu belirlenen yerlerde Türkler tarih boyunca yaylak ve kışlak olarak konakladı. Nitekim Oğuzların yaylak yerleri olduğu gibi diğer İran, İlhanl, Avşar Türkleri için de önemli bir yer teşkil ettii. ${ }^{74}$

Oğuz Kağan Destanı'nda, Türk töresi gereği, birçok bölge ele geçirildikten sonra bu bölgelerin paylaştırılması (ülüşleştirilmesi) hakkında da önemli bilgiler verildi. Mesela destanda,

“Bir gün Irgıl Hoca Kün Han’a dedi ki: Oğuz büyük bir kağandı ve yeryüzünü idaresi altına alıp pek çok hazine ve saylsız hayvan topladı. Şimdi onların hepsi sizindir. Siz altı oğlun, Tanrının izniyle her birinizin dörder taneden yirmi dört evladınız var. Olabilir ki onlar sonradan birbirleriyle çekişirler. Bunun çaresi, her birinin rütbesi, mesleği, adı ve lakabı kararlaşsın; her birinin bir nişanı ve tamgası olsun. Bununla bilinip taninsınlar ve hiçbirinin diğeriyle bir çekişmesi olmasın, Onların evladının da her biri kendi yerini bilsinler. Bunu yapmak devletin devamlılığı ve uruğunuzun iyi nam kazanmasının gereğidir."

Bu sözler Kün-Han'a çok uygun gelmiş ve Kün- Han Irgıl Hoca'ya söylediklerini yerine getirmesini emretti. Irgıl Hoca daha Oğuz'un hayatta iken Gün, Ay, Yıldız oğullarının topluluğuna Bozok, Gök, Dağ, Deniz oğullarının topluluğuna Üçok ismini alan bu oğullardan olan tam yirmi dört evladın her birine birer lakap verdi; yine birbirine bunlardan kime ait olduğunu belirtmek üzere hayvanlara vurmak için birer tamga tespit etti. Her bir oğula hangi hayvanın ongun olacağını da belirtti. ${ }^{75}$ Böylece her boyun tamgası ve ülüşü Irgıl Hoca sayesinde belirlenmiş oldu. Irgıl Hoca at etinden hangi boya hangi parçanın ülüş olarak verileceğini, bir daha hiçbir anlaşmazlık ve dedikodu olmaması için tespit etti. Bir toy yapılacağı zaman iki at kesildi. At on iki parçaya ayrılabildiğinden bir atı Bozoklara, diğer atı da Üçoklara versinler. Boyuna yakın olan bir arka kemiği, arkaya yakın olan sırt omurgası ve bir sağ kol hükümdarın ve milletin büyügünün hissesi oldu. Diğer parçalar ise her boya ve Oğuz'un oğullarına has ülüş olarak ayrılıp verildi. Bu şekilde tafsilat her kabilenin altına yazıldı. Ayrıca Oğuz oğulları şöyle emrettiler: Sağ kol olan Bozoklar, Sayram sınırları ve Başgurd Dağları'ndan Karabah (Karaağaç)'a kadar yaylak edinsinler. Kış̧ık yerler olarak sağ kol için Borsuk ${ }^{76}$, Aktag, Namalmış ve Basakumı tayin olundu. Sol kol olan Üçoklara ise yaylak olarak, Kürtag, Yeryud, Tuğluk ve Bozyaka'dan Almalık'ın Akdağı'na kadar olan yerler ayrıldı. Qayı (Qarlu) Dere, Asanaş, Qum Sengri, Qayı Durdu ve Yar Sengri kışlak olarak ayrildı. ${ }^{77}$

Oğuz Kağan Destanı'nda boy teşkilatları ve merkeziyetçi devletin kuruluş ve genişleme çerçevesinde töre ve ülüş- orun meselesiyle yaylak ve kışlak alanların yakından ilişkili olduğu görüldü. Zeki Veli Togan, Oğuz Kağan Destanı'nı tercümesinde yaylak ve kışlakları ile ilgili yer adlarının çözülmesinde güçlük çekildiğini belirtmektedir. Ancak nüshalarda okunabilen kısımlarından Almalık Üçokların önemli yaylak yerlerinden biri olduğunu Bozokların yaylaklarının Sayram, Kazgurt dağlarında Kara Dağlar’a kadar olan kısımları teşkil ettiğini kışlaklarını ise Borsuk ve Ak Dağlar olarak verilen yerler olduğunu belirtmektedir. ${ }^{78}$ Böylece yaylak ve kışlakların yerleri ve sınırları ülüş olarak her bir Oğuz boyu için belirlenmiştir. Herhangi bir düzensizlik, kargaşa ve belirsizlik yoktur, göçebe tanımı gereği başıboş gezme mümkün değildir.

\footnotetext{
${ }^{70}$ Gündüz, age, s. 79.

${ }^{71}$ Togan, Oğuz Destanı.., s. 46.

${ }^{72}$ Togan, Ŏguz Destanı.., s. 41-42.

${ }^{73}$ Togan, Oğuz Destanı.., s. 45-46.

${ }^{74}$ Togan, Oğuz Destani.., s. 100.

${ }^{75}$ Togan, Oğuz Destanı.., s. 49-50.

${ }^{76}$ Burası hem Oğuz Destanı'nda hem de Cengiz Han dönemi Cuci seferlerinin anlatıldığı Karakum şehri kışlak olarak geçmektedir. Bkz.

Togan, Bugünkü Türk Illi..., s. 17-18.

${ }^{77}$ Togan, Ŏguz Destani.., s. 52-53.

${ }^{78}$ Ögel, Türk Mitolojisi, C.1., s. 153-154.
} 


\section{SONUÇ}

Oğuz Kağan Destanı, Türk yaşam biçimini yansıtan önemli örneklerden biridir. Destan, Oğuz Kağan'ın cihanı ele geçirme arzusunu, bu arzuyu gerçekleştirme yolunda teşkilatçılığını ortaya koyar. Oğuz Kağan Destanı boyunca Oğuz Kağan tarafından gerçekleştirilen devlet kurma ve teşkilatlandırması aslında onu yaratan toplumun töre ve yaşayışına uygun hareket etmesinden kaynaklandığı söyleyebilir. Makalede, Türklerin atlı göçerevli yaşam, Oğuz Kağan Destanı'na göre diğer millet ya da toplulukların göçebeliği gibi olmadığı Türklerin yaşadıkları coğrafya ve hayvancıllğa göre şekillendiği görüldü. Türkler, yaz aylarında hayvanlarını otlatabilecekleri yaylaklara giderken kışın daha sıcak bölgelere kışlaklara göç etti. Yaylak ve kışlaklar belirlenirken orun (mevki) - ülüşler (paylaşım)'in töreye uygun, yani adaletli ve düzenli şekilde yapıldığı görüldü. Destan, batılı ve diğer araştırmacılar tarafindan "göçebe / barbar" olarak nitelendirilen Türklerin, göçebelikten ziyade atlı göçerevli yaşamını ve teşkilatçılı̆ı̆ıı ortaya koymaktadır. Bu hususta, atlı göçerevli hayatın, aileleriyle ve boylarıyla birlikte gerçekleştirildiği gibi yaylak - kışlak alanların belirli olduğu, sosyal düzenin oluşmasına katkı sağladı.

Oğuz Kağan, atlı göçerevli bir toplumun beklentilerini ve özelliklerini anlatırken birçok yeri yurt edindiği ve uygun bulduğu yerlerde yaylak ve kışlaklar kurduğu görülür. Destanda Oğuz'un anayurt topraklarını kendi oğulları arasında yaylak ve kışlak olarak belirlerken yeni aldığı topraklarda da kendi isimlendiği Türk boylarına yurt ve yaylak - kışlaklar verir. Oğuz Kağan'ın, seferlere çıktığında yol üzerinde de askerleri ve atları için yaylak ve kışlaklar seçtiği, yaşam tarzını o bölgelere taşıdığı anlaşılır. Sonuç olarak, Türklerin yaşamlarını sürdürebilmelerinde sık otlaklar, serin su kaynakları, dağlar ve taze otu hiç bitmeyen vadi ve irmaklar önemlidir. $\mathrm{Su}$ kenarları, ırmaklar Oğuz boylarının kışlak yerleri iken dağlar da bunların önemli yaylak yerlerini oluşturmaktadır. Oğuzların teşkilatlanmasında sağ kol olarak bilinen Bozoklar, Sayram bölgesini, Başgurd dağlarından Karabag (Karaağaç)'a kadar olan bölgeyi yaylak olarak aldı. Kışlaklar ise Borsuk, Aktag, Namalmış ve Basakumı olarak belirlendi. Sol kol olarak bilinen Üçoklara ise yaylak olarak Kürtaq, Yeryud, Tuğluk, Bozyaka, Almalık Akdağı'na kadar olan yerler ayrıldı. Kışlaklar ise Kayı Dere (Karlu), Asanaş, Kum Sengri, Kayı Durdu ve Yar Sengri bölgeleridir. Oğuz Kağan Destanı'nda yaylak ve kışlaklar, Bozok, Üçok veya isim verdiği Türk boylarının yaşam alanlarını belirledi, bu bölgeler geleneksel ve tarihi yurtları hâline geldi.

\section{KAYNAKÇA}

AGACANOV, Sergey Grigoreviç, Oğuzlar, çev. Ekber N. Necef, Ahmet Annaberdiye, Selenge Yayınları, İstanbul 2002.

BANARLI, Nihad Sami, Resimli Türk Edebiyatı Tarihi, Milli Eğitim Basımevi, C. 1, İstanbul 1983.

BAYAT, Fuzuli, “Oğuz Kağan Destanı Üzerine Yeni Düşünceler”, Türkler Ansiklopedisi, C. 4, Yeni Türkiye Yayınları, Ankara 2002, ss.520-526.

BAYKARA, Tuncer, "Göktürk Yazıtlarının Türk İskân (Yerleşme) Tarihindeki Yeri”, Türk Dili Araştırmaları Ylllığ $\breve{g}_{-}$Belleten, C. 38, 1990, ss.17-29.

BİRAN, Michal, "Nomads as Agents Of Culturel Change, The Mongols and Eurasians Predecessors Nomadic Culture”, Edited By. Reuven Amitai, Michal Biran, University of Hawai'i Press, Honolulu, 2015, pp.19 .

DEER, Jozsef, "İstep Kültür", çev. Şerif Baştav, Ankara Üniversitesi Dil ve Tarih-Coğrafya Fakültesi Dergisi, C. 12, S. 1-2, 1954, ss.159-176.

DEMIRCİ, Hikmet ve Şınaray Bürkütbayeva, "Kazak Misafirperverliği: Ülüş, Misafir Ağırlama ve Tabak Kültürü”, Milli Folklor Dergisi, 2020, Y. 32, S. 126, Ankara 2020, ss.198- 209.

DURMUŞ, İlhami, “Türk Kültür Çevresinde Kültür Adlandırmaları”, Gazi Akademik Bakş̧ Dergisi, C. 8, S. 15, 2014, ss.269-298.

ERGİN, Muharrem, Dede Korkut Kitabı, Millî Eğitim Bakanlığı Yayınevi, İstanbul 1971.

ESIN, Emel, İslamiyet'ten Önceki Türk Kültür Tarihi ve İslam'a Giriş, Edebiyat Fakültesi Matbaası, İstanbul 1978.

GÖKALP, Ziya, Türk Medeniyet Tarihi, Haz. İsmail Aka, Kazım Yaşar Kopraman, Kültür Bakanlığı Yayınevi, İstanbul 1976.

GÜLENSOY, Tuncer, Türkiye Türkçesindeki Türkçe Sözcüklerin Köken Bilgisi Sözlügü̈, Türk Dil Kurumu Yayınları, C. 1, Ankara 2007. 


\section{OĞUZ KAĞAN DESTANI'NDA İSKÂN: YAYLAK VE KIŞLAKLAR}

GÜMÜŞÇÜ, Osman, "Yaylak ve Kışlak”, TDV İA, C. 2, ss.669-670.

GÜNDÜZ, Tufan, Oğuz Kağan Destanı, Yeditepe Yayınları, İstanbul 2019. 133.

İNAN, Abdulkadir, "Orun” ve Ülüş Meselesi”, Türk Hukuk ve İktisat Mecmuasl, İstanbul 1931, ss.121-

İNAN, Abdulkadir, "Türk Düğünlerinde Exogamie İzleri”, Makaleler ve İncelemeler, C.1., Türk Tarih Kurumu Basımevi, Ankara 1968, s.341-349.

KAFESOĞLU, İbrahim, Türk Milli Kültürü, Ötüken Neşriyat Yayınları, İstanbul 1998.

KAFESOĞLU, İbrahim, Türk Bozkır Kültürü̈, Türk Kültürü Araştırma Enstitüsü, Ankara 1987. 519.

KAPLAN, Mehmet, “Oğuz Kağan- Oğuz Han Destanı”, Türkler Ansiklopedisi, C. 3, Ankara 2003, ss.511-

KARATAY, Osman, Illk Oğuzlar, Köken, Türeyiş ve Erken Tarihi Üzerine Çalışmalar, Ötüken Yayınları, İstanbul 2017.

KAŞGARLI, Mahmud, Divanü Lügat-it Türk Tercümesi, C.III, çev. Besim Atalay, Türk Dil Kurumu Yayınları, Ankara 1941.

KAYALI, Özcan, 8. 11. Yüzyıllar Arasında Göçebe Türklerin Yaylak ve Kışlak Hayatı, Marmara Üniversitesi Türkiyat Araştırmaları Enstitüsü (Yayımlanmamış Yüksek Lisans Tezi), İstanbul, 2010, s. 29Yüksek Lisans Tezi, İstanbul 2010.

KHAZANOV, Anatoly M., Göçebe ve Dlş Dünya, çev. Ömer Suveren, Doğu Kütüphanesi Yayınları, İstanbul 2015.

KRADİN, Nikolai N., Nomadism, Evolution and World -System: Pastoral Societies in Theories of Historical Development, Journal of World Systems Research, 8,(3), 2002, ss.368-388.

KOCA, Salim, Türk kültürünün Temelleri, Ötüken Yayınevi, İstanbul 2007.

KÖPRÜLÜ, M. Fuad, Türk Edebiyat Tarihi, Ötüken Yayınları, İstanbul 1980.

KÜTÜKOĞLU, Mübahat S., Tarih Araştırmalarında Usûl, Türk Tarih Kurumu Yayınları, 2. Basım, Ankara 2017.

OĞUZ, M. Öcal, "Destan Tanımı ve Eski Türk Destanları", Milli Folklor Dergisi, Y.16, S. 62, Ankara 2004, ss.5-7.

ÖGEL, Bahaeddin, Türk Mitolojisi, Türk Tarih Kurumu Basımevi, C. 1, Ankara 2010.

ÖGEL, Bahaeddin, Türk Mitolojisi, Türk Tarih Kurumu Basımevi, C. 2, Ankara 1995.

ÖGEL, Bahaeddin, Türk Kültür Tarihine Giriş I., Kültür ve Turizm Bakanlığı Yayınları, Ankara 1978.

ROUX, Jean Paul, Türklerin Tarihi: Pasifik'ten Akdeniz'e 2000 Yll, çev. Aykut Kazancıgil, Lale Arslan Özcan, Kabalcı Yayınları, İstanbul 2017.

RASONYI Laszlo, Tarihte Türkler, Türk Kültürünün Araştırma Enstitüsü, Ankara 1993.

SEZER, Baykan, Asya Tarihinde Su Boyu Ovalarl ve Bozkır Uygarliklarl, Edebiyat Fakültesi Basımevi, İstanbul 1979.

ŞEN, Mesut, "Türklerde Kışlag ve Yaylag Kavramları Üzerine Düşünceler", Çukurova Üniversitesi Türkoloji Araştırmaları Dergisi, C. 3, S.2, 2018, ss.131-148.

TOGAN, Zeki Velidi, Umumi Türk Tarihine Giriş, Enderun Kitapevi, İstanbul Üniversitesi Edebiyat Fakültesi Yayınları, İstanbul 1981.

TOGAN, Zeki Velidi, Bugünkü Türk IIli (Türkistan) ve Yakın Tarihi), C.1, Güven Basımevleri, İstanbul 1942.

TOGAN, Zeki Velidi, Oğuz Destant-Reşideddin Oğuznamesi, Tercüme ve Tahlili, Enderun Yayınları, İstanbul 1982.

TURAN, Osman, Türk Cihan Hakimiyeti Mefkuresi Tarihi, Ötüken Yayınları, İstanbul 2014. 


\section{HIKKMET DEMIRCI-SELIME INNAN}

ÜLKEN, Hilmi Ziya, Sosyoloji Sözlüğü, Milli Eğitim Basımevi, İstanbul 1969.

YILMAZ, Anıl ve Cahit Telci, “Türk Kültür Terminolojisinde Göç Kavramı Üzerine”, Modern Türklük Araştırmaları Dergisi, C. 7, S. 2, 2010, ss.14-33. 
OĞUZ KAĞAN DESTANI'NDA İSKÂN: YAYLAK VE KIŞLAKLAR 